\title{
Water-soluble Calix[4]resorcinarenes with Hydroxyproline Groups as Chiral NMR
}

\section{Solvating Agents}

Courtney M. O'Farrell, J. Matthew Chudomel, Jan M. Collins, Catherine F. Dignam and Thomas J. Wenzel*, Department of Chemistry, Bates College, Lewiston, ME 04240 twenzel@bates.edu

\section{Supporting Information - Table of Contents}

Page

S2 - Procedures

$\mathrm{S} 3 \quad-{ }^{1} \mathrm{H}$ NMR spectrum $\left(400 \mathrm{MHz}, \mathrm{D}_{2} \mathrm{O}, 23{ }^{\circ} \mathrm{C}\right)$ of cis-4-hydroxy-D-proline derivative (3)

$-{ }^{1} \mathrm{H}$ NMR spectrum $\left(400 \mathrm{MHz}, \mathrm{D}_{2} \mathrm{O}, 23{ }^{\circ} \mathrm{C}\right)$ of cis-4-hydroxy-L-proline derivative (4)

S4 - ${ }^{1} \mathrm{H}$ NMR spectrum $\left(400 \mathrm{MHz}, \mathrm{D}_{2} \mathrm{O}, 23{ }^{\circ} \mathrm{C}\right)$ of trans-4-hydroxy-L-proline derivative (5)

- ${ }^{1} \mathrm{H}$ NMR spectrum $\left(400 \mathrm{MHz}, \mathrm{D}_{2} \mathrm{O}, 23{ }^{\circ} \mathrm{C}\right)$ of trans-3-hydroxy-L-proline derivative (6)

S5 - ${ }^{1} \mathrm{H}$ NMR spectrum $\left(400 \mathrm{MHz}, \mathrm{D}_{2} \mathrm{O}, 23{ }^{\circ} \mathrm{C}\right)$ of nipecotic acid derivative $(7)$

$-{ }^{1} \mathrm{H}$ NMR spectrum $\left(400 \mathrm{MHz}, \mathrm{D}_{2} \mathrm{O}, 23{ }^{\circ} \mathrm{C}\right)$ of $(S)$-methoxymethyl pyrrolidine derivative (8)

S6 $\quad-{ }^{1} \mathrm{H}$ NMR spectrum $\left(400 \mathrm{MHz}, \mathrm{D}_{2} \mathrm{O}, 23^{\circ} \mathrm{C}\right)$ of $(S)$-pyrrolidine methanol derivative (9)

$-{ }^{1} \mathrm{H}$ NMR spectrum $\left(400 \mathrm{MHz}, \mathrm{D}_{2} \mathrm{O}, 23{ }^{\circ} \mathrm{C}\right)$ of $(\mathrm{S}, \mathrm{S})$-bismethoxy methyl pyrrolidine derivative (10) 
S7 -Job plots for 24 with 6 and for 30 with 6.

Procedures. ${ }^{1} \mathrm{H}$ NMR spectra were recorded at $400 \mathrm{MHz}$ using 16 scans at ambient probe temperature $\left(23^{\circ} \mathrm{C}\right)$. Samples for NMR spectroscopy were prepared by weighing and dissolving the appropriate amount of substrate in deuterium oxide. Increments of the calix[4]resorcarene were added either by weight or volumetrically by addition of an appropriate amount of a concentrated stock solution (120 mM or $240 \mathrm{mM})$. Aggregation studies involved recording spectra of successive dilutions of a $10 \mathrm{mM}$ solution of the calix[4]resorcinarene in $\mathrm{D}_{2} \mathrm{O}$. Stoichiometries of complexes with 1 were determined using Job's method ${ }^{16}$. The concentration of $\mathbf{1}$ and substrate are continuously varied throughout the series while maintaining a total concentration of $\mathbf{1}$ and substrate of $40 \mathrm{mM}$ for each sample. Association constants were determined using the Scatchard method (Foster-Fyfe) of infinite dilutions of host (1) while maintaining the concentration of substrate at $2 \mathrm{mM}^{17}$. The use of the Scatchard method for determining association constants is recommended over other graphical techniques ${ }^{18}$. The concentration of $\mathbf{1}$ was varied from 50 to $1 \mathrm{mM}$ for the series of spectra by diluting with a $2 \mathrm{mM}$ solution of the substrate. 


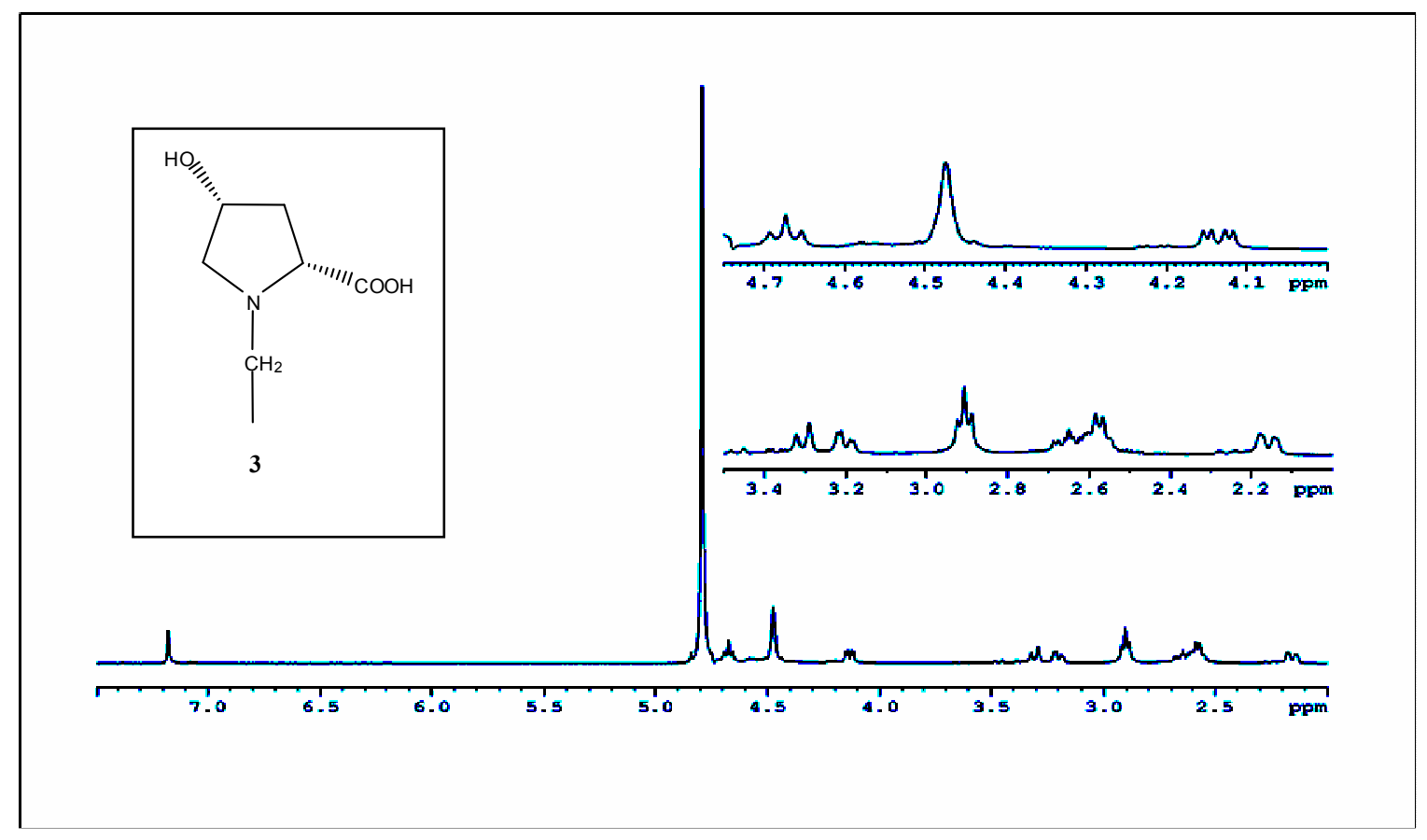

${ }^{1} \mathrm{H}$ NMR spectrum (400 MHz, $\mathrm{D}_{2} \mathrm{O}, 23{ }^{\circ} \mathrm{C}$ ) of SCR-cis-4-hydroxy-D-proline (3)

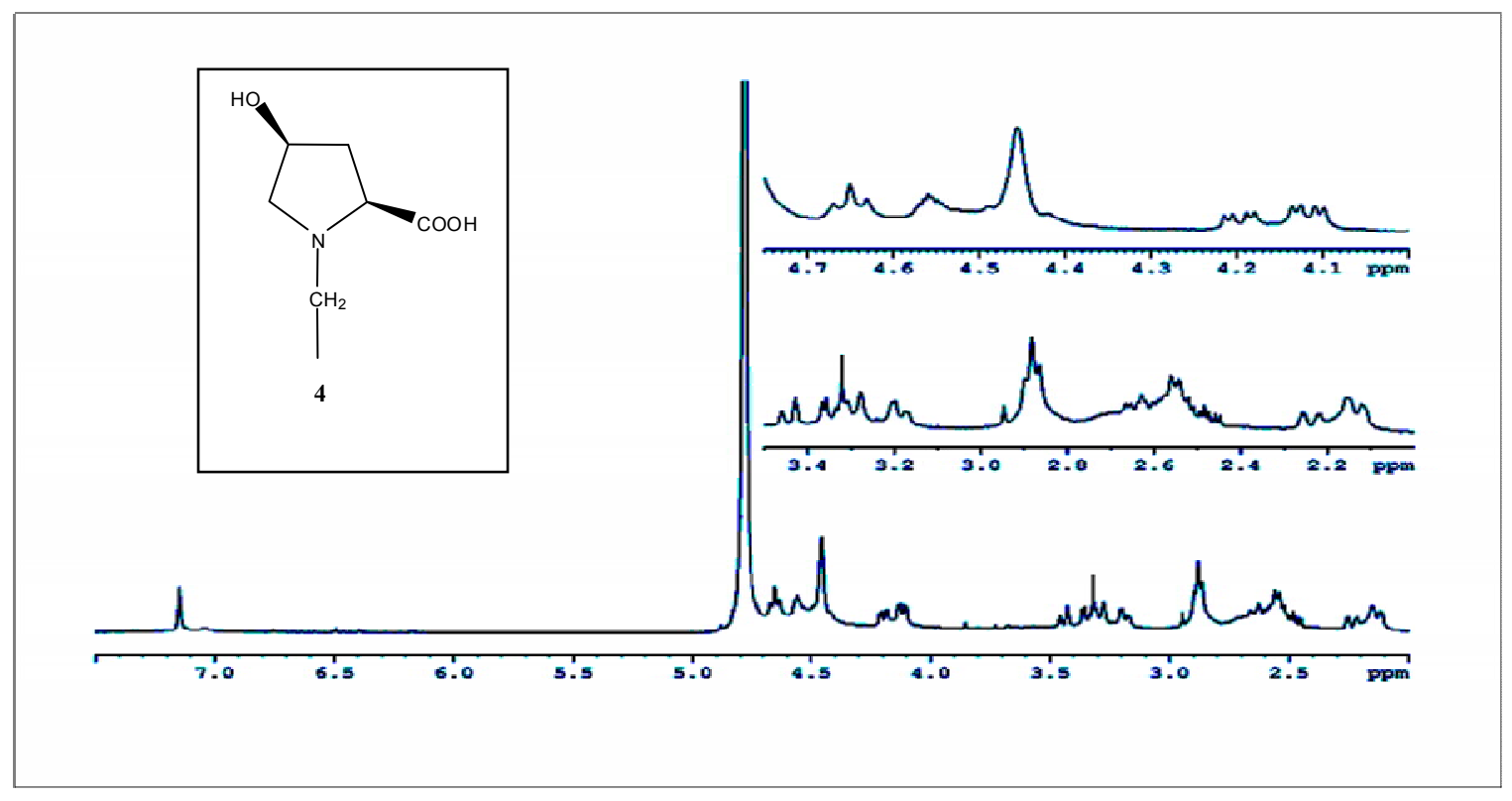

${ }^{1} \mathrm{H}$ NMR spectrum $\left(400 \mathrm{MHz}, \mathrm{D}_{2} \mathrm{O}, 23{ }^{\circ} \mathrm{C}\right.$ ) of SCR-cis-4-hydroxy-L-proline (4) 


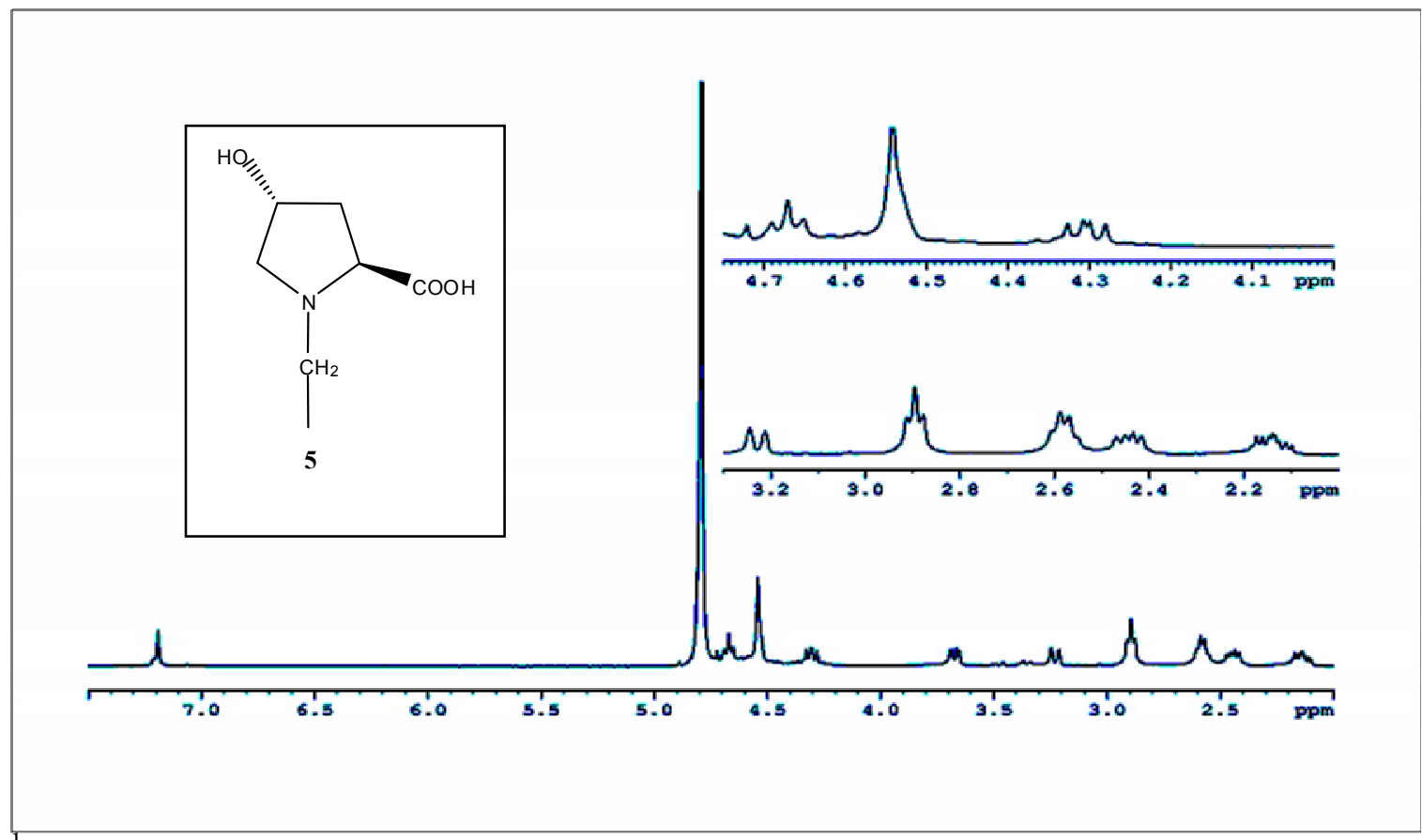

${ }^{1} \mathrm{H}$ NMR spectrum $\left(400 \mathrm{MHz}, \mathrm{D}_{2} \mathrm{O}, 23{ }^{\circ} \mathrm{C}\right)$ of SCR-trans-4-hydroxy-L-proline (5)

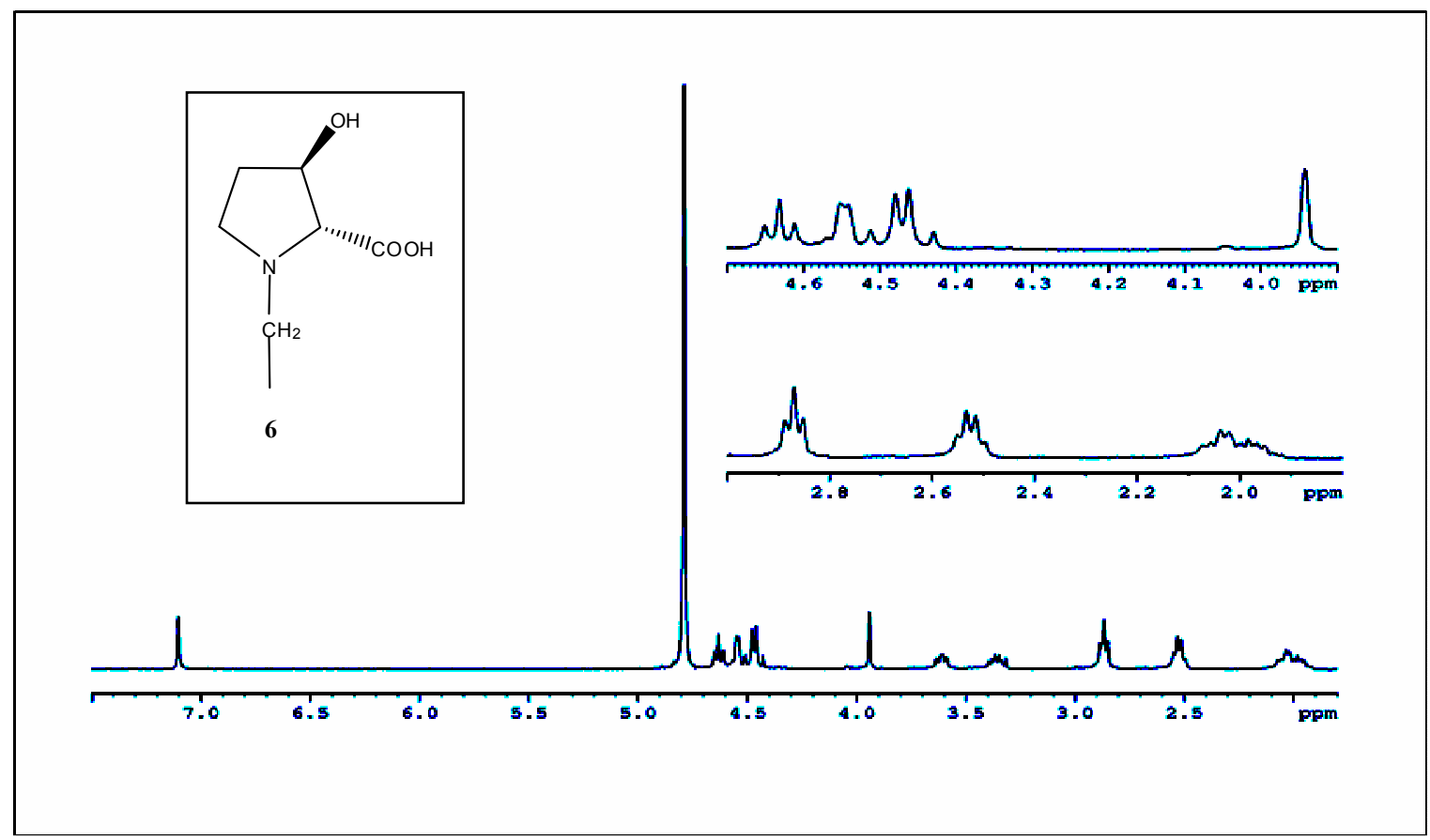

${ }^{1} \mathrm{H}$ NMR spectrum $\left(400 \mathrm{MHz}, \mathrm{D}_{2} \mathrm{O}, 23{ }^{\circ} \mathrm{C}\right)$ of SCR-trans-3-hydroxy-L-proline (6) 


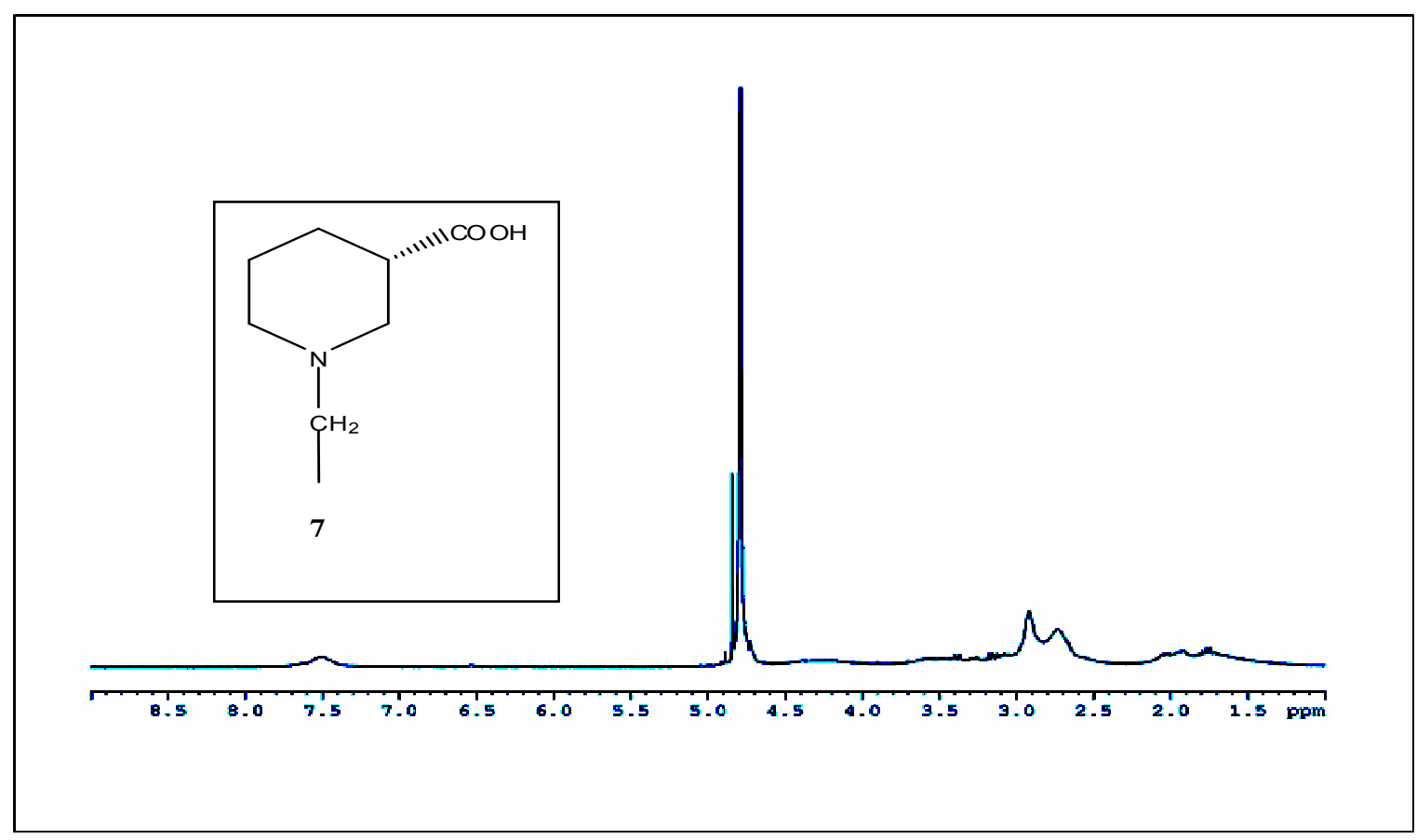

${ }^{1} \mathrm{H}$ NMR spectrum $\left(400 \mathrm{MHz}, \mathrm{D}_{2} \mathrm{O}, 23{ }^{\circ} \mathrm{C}\right)$ of SCR-nipecotic acid (7)

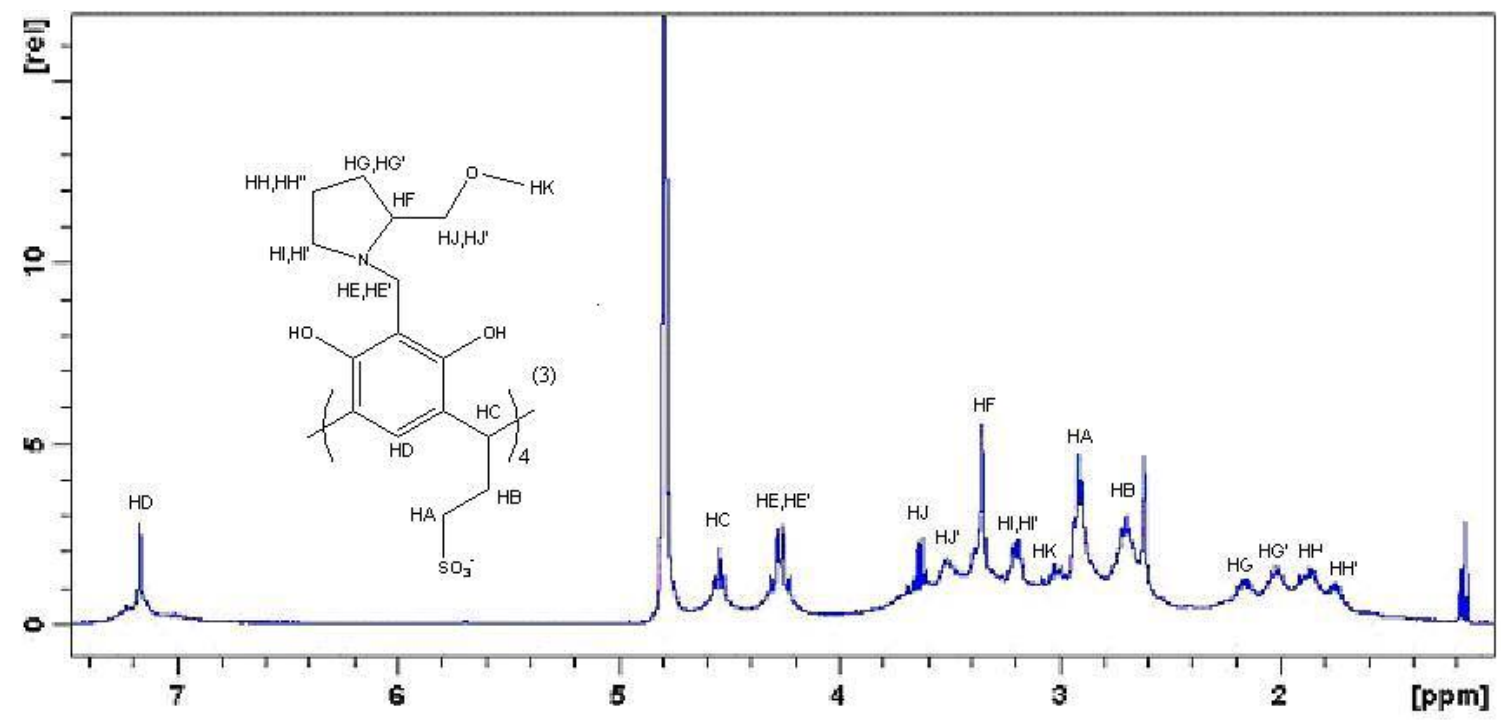

${ }^{1} \mathrm{H}$ NMR spectrum of sulfonated calix[4]resorcarene derivatized with S-methoxymethyl pyrrolidine in $\mathrm{D}_{2} \mathrm{O}(\mathbf{8})$. 


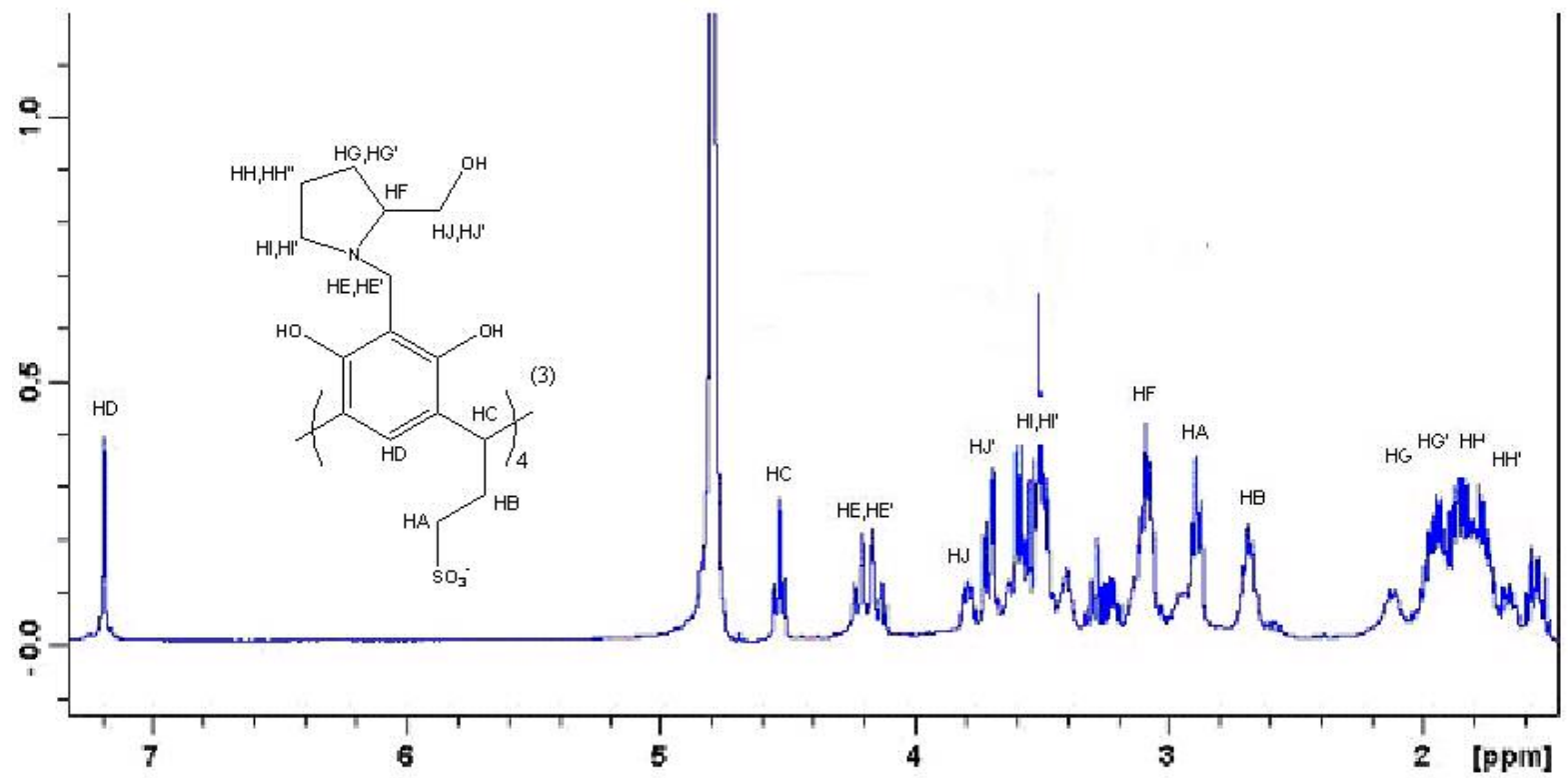

${ }^{1} \mathrm{H}$ NMR spectrum of sulfonated calix[4]resorcarene derivatized with S-Pyrrolidine Methanol in $\mathrm{D}_{2} \mathrm{O}$ (9).

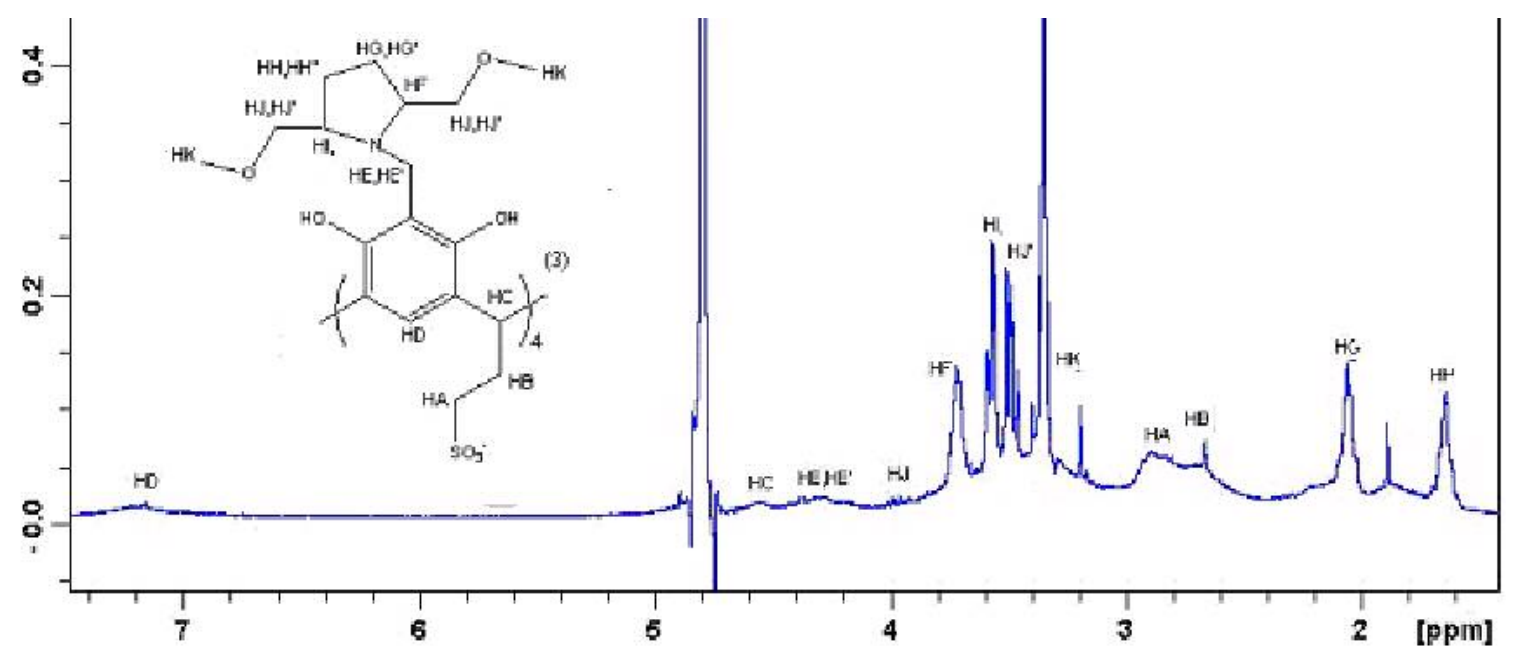

${ }^{1} \mathrm{H}$ NMR spectrum of sulfonated calix[4]resorcarene derivatized with S-S-bismethoxy methyl pyrrolidine $\mathrm{D}_{2} \mathrm{O}(\mathbf{1 0})$. 

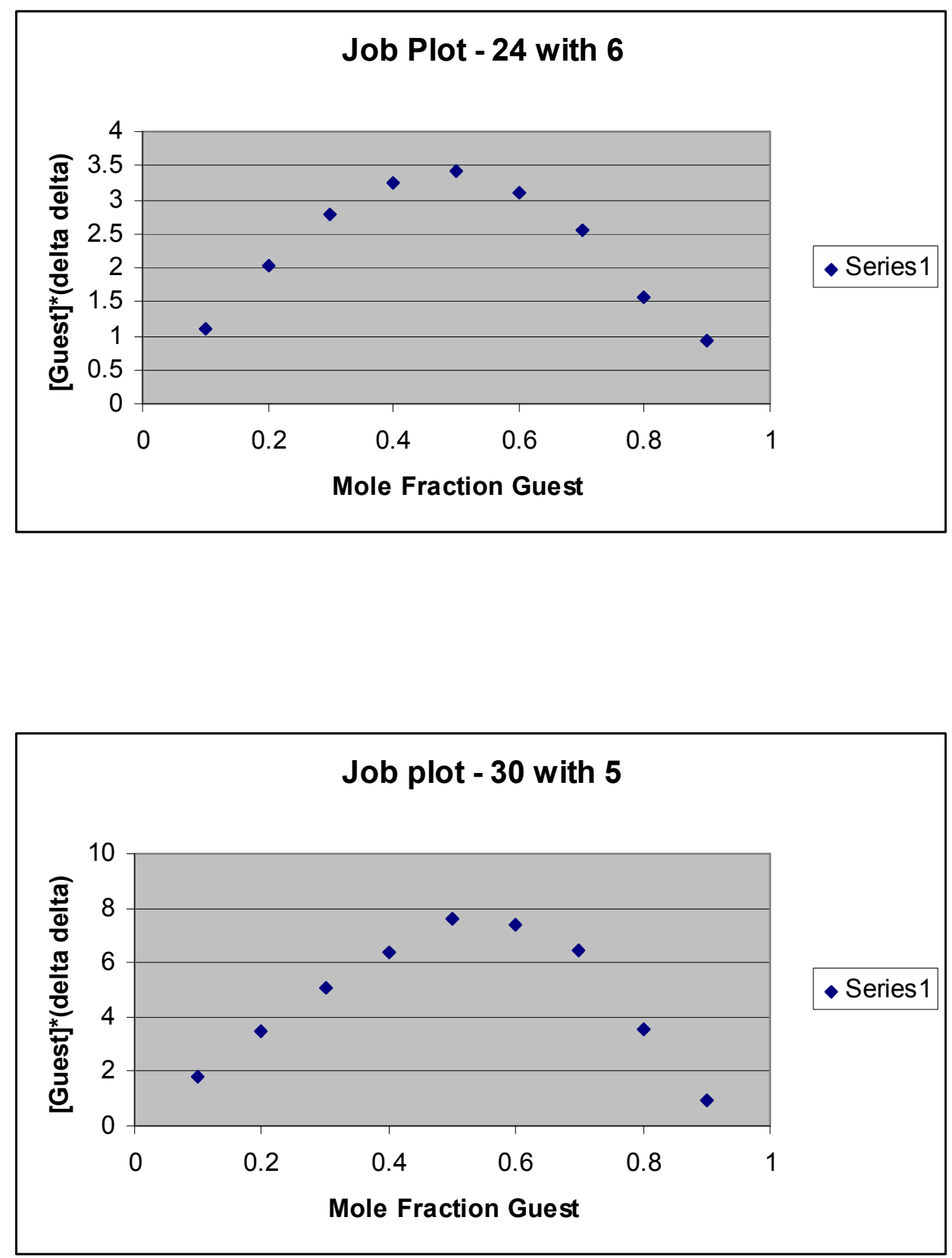